\title{
Heparin cofactor II inhibits arterial thrombosis after endothelial injury
}

\author{
Li He, ${ }^{1}$ Cristina P. Vicente, ${ }^{1}$ Randal J. Westrick, ${ }^{2}$ Daniel T. Eitzman, ${ }^{2}$ \\ and Douglas M. Tollefsen ${ }^{1}$
}

${ }^{1}$ Division of Hematology, Department of Internal Medicine, and Department of Biochemistry and Molecular Biophysics,
Washington University, St. Louis, Missouri, USA
${ }^{2}$ Division of Cardiology, Department of Medicine, University of Michigan, Ann Arbor, Michigan, USA

Address correspondence to: Douglas M. Tollefsen, Division of Hematology, Box 8125,

Washington University School of Medicine, 660 South Euclid Avenue, St. Louis, Missouri 63110, USA.

Phone: (314) 362-8830; Fax: (314) 362-8826; E-mail: tollefsen@im.wustl.edu.

Received for publication June 4, 2001, and accepted in revised form December 3, 2001.

\begin{abstract}
Heparin cofactor II (HCII) is a plasma protein that inhibits thrombin rapidly in the presence of dermatan sulfate, heparan sulfate, or heparin. HCII has been proposed to regulate coagulation or to participate in processes such as inflammation, atherosclerosis, and wound repair. To investigate the physiologic function of HCII, about $2 \mathrm{~kb}$ of the mouse $\mathrm{HCII}$ gene, encoding the $\mathrm{N}$-terminal half of the protein, was deleted by homologous recombination in embryonic stem cells. Crosses of $\mathrm{F}_{1} \mathrm{HCII}^{+/-}$animals produced $\mathrm{HCII}^{-/-}$offspring at the expected mendelian frequency. Biochemical assays confirmed the absence of dermatan sulfate-dependent thrombin inhibition in the plasma of $\mathrm{HCII}^{-/-}$animals. Crosses of $\mathrm{HCII}^{-/-}$animals produced litters similar in size to those obtained from heterozygous matings. At 1 year of age, HCII-deficient animals were grossly indistinguishable from their wild-type littermates in weight and survival, and they did not appear to have spontaneous thrombosis or other morphologic abnormalities. In comparison with wild-type animals, however, they demonstrated a significantly shorter time to thrombotic occlusion of the carotid artery after photochemically induced endothelial cell injury. This abnormality was corrected by infusion of purified HCII but not ovalbumin. These observations suggest that HCII might inhibit thrombosis in the arterial circulation.
\end{abstract}

J. Clin. Invest. 109:213-219 (2002). DOI:10.1172/JCI200213432.

\section{Introduction}

Heparin cofactor II (HCII) is a serine protease inhibitor (serpin) that inactivates thrombin rapidly in the presence of certain glycosaminoglycans (reviewed in ref. 1). HCII does not inhibit other proteases involved in coagulation or fibrinolysis. Thrombin stimulates platelet aggregation, promotes coagulation by cleavage of fibrinogen and activation of factors V, VIII, XI, and XIII, and inhibits fibrinolysis by activation of a plasma carboxypeptidase (2). Conversely, when thrombin binds to thrombomodulin on the surface of endothelial cells, it activates protein C, which inhibits further thrombin generation. Thrombin also engages in a variety of activities unrelated to hemostasis (3). For example, it causes proliferation of fibroblasts and other cells, induces monocyte chemotaxis, promotes adhesion of neutrophils to endothelial cells, and inhibits neurite outgrowth. HCII could potentially regulate the activity of thrombin in one or more of these diverse biological processes.

The rate of inhibition of thrombin by HCII increases more than 1000-fold in the presence of heparin, heparan sulfate, or dermatan sulfate (4). HCII is unique among serpins in its ability to be stimulated by dermatan sulfate and binds to a minor subpopulation of dermatan sulfate oligosaccharides (5). By contrast, antithrombin binds to a specific pentasaccharide structure in heparin or heparan sulfate and is thereby stimulated to inhibit thrombin and other coagulation proteases (especially factors Xa and IXa) (1). The distribution of specific glycosaminoglycans on the cell surface or in the ECM may serve to localize protease inhibition by HCII and antithrombin to different sites. Cultured fibroblasts and vascular smooth muscle cells synthesize proteoglycans that stimulate inhibition of thrombin by HCII, but endothelial cells do not, suggesting that HCII may inhibit thrombin at sites outside the vascular lumen $(6,7)$.

Although the physiologic function of $\mathrm{HCII}$ is unknown, the presence of thrombin-HCII complexes in human plasma indicates that HCII inhibits thrombin in vivo $(8,9)$. HCII is synthesized by the liver and circulates in human plasma at a concentration of about 1 $\mu \mathrm{M}(10)$. Turnover studies of labeled HCII in humans suggest that about $40 \%$ of the protein equilibrates with an extravascular compartment (11), but the tissue distribution of HCII has not been thoroughly investigated. HCII has been detected in the intima of normal human arteries, and the ability of dermatan sulfate in the arterial wall to stimulate HCII is decreased in atherosclerotic lesions $(12,13)$. During pregnancy, both the maternal and the fetal blood contain trace amounts of a dermatan sulfate proteoglycan that stimulates thrombin inhibition by HCII (14). The placenta is rich in der- 
matan sulfate and may be the source of the circulating proteoglycan, suggesting that HCII could be activated locally to inhibit coagulation in the placenta (15). Chemotactic peptides are released when HCII is partially degraded by neutrophil proteases, suggesting a possible direct role for HCII in inflammation (16). HCII could also participate in wound healing by regulating the mitogenic or chemotactic activities of thrombin.

Several patients with inherited HCII deficiency $(\sim 50 \%$ of normal) and histories of venous thromboembolic disease have been reported $(17,18)$. In one study, however, 4 of 379 apparently healthy individuals had HCII levels less than $60 \%$ of normal (19). Thus, heterozygous deficiency of HCII may be a coincidental finding in about $1 \%$ of patients with venous thrombosis and does not appear to be a strong risk factor for development of this disease (20). Two sisters who appeared to be homozygous for HCII deficiency (HCII activity $10-15 \%$ of normal) have been reported (21); one of these individuals was also heterozygous for antithrombin deficiency and had recurrent venous thromboembolism. Human subjects who completely lack HCII have not been identified.

With the aim of elucidating the physiologic function(s) of HCII, we have generated a mouse model of HCII deficiency by targeted gene disruption in embryonic stem cells. HCII-deficient mice are viable and fertile, and they do not appear to have spontaneous thrombosis or other morphologic abnormalities. In comparison with wildtype animals, however, they demonstrate a significantly shorter time to thrombotic occlusion of the carotid artery after photochemically induced endothelial cell injury. These observations suggest that a function of HCII might be to inhibit thrombosis in the arterial circulation.

\section{Methods}

Construction of the targeting vector. PCR primers (5'-CTTCTTTCTCTCATCACATTTATG and 5'-CTTGGAAAAGCTGCAGGATGTTG) that amplify a 271-bp fragment in exon 1 of the mouse HCII gene (22) were used to screen a bacterial artificial chromosome (BAC) library made from 129/SvJ mouse genomic DNA (Genome Systems Inc., St. Louis, Missouri, USA). Two clones were isolated, each containing more than $100 \mathrm{~kb}$ of genomic DNA. A 6-kb EcoRV fragment that included about $3 \mathrm{~kb}$ of $5^{\prime}$ flanking sequence, exon 1 , and about $2 \mathrm{~kb}$ of intron 1 was isolated from one of the BAC clones and subcloned into the EcoRV site of pBluescript II SK(+) (Stratagene, La Jolla, California, USA). The vector was then cleaved with EcoRI to remove the exon 1 and intron 1 sequences and ligated to a $1.6-\mathrm{kb}$ EcoRI fragment of pPGKneo-I (Embryonic Stem Cell Core, Washington University), which contained the phosphoglycerate kinase promoter and the neomycin phosphotransferase gene (neo) flanked by loxP sequences. Ligation of the neo cassette occurred in the same transcription orientation as the $H C I I$ gene. A 4-kb $B a m H I$ fragment extending from the middle of intron 1 through intron 3 of the HCII gene was isolated from the other BAC clone and inserted into the BamHI mul- tiple cloning site of pBluescript to yield the targeting vector shown in Figure 1a. The final construct contained a $5^{\prime}$ arm of $2.9 \mathrm{~kb}$ and a $3^{\prime}$ arm of $3.6 \mathrm{~kb}$ of HCII genomic sequence flanking the neo cassette.

Generation of HCII-deficient mice. The targeting vector was linearized with NotI and introduced into 129/SvJderived RW-4 embryonic stem cells (Embryonic Stem Cell Core, Washington University) by electroporation. G418-resistant clones were screened for homologous recombination at the HCII locus by Southern hybridization of SacI digests, using a 329-bp probe (3'probe) to a DNA sequence in exon 4 and an approximately 500 -bp probe ( $5^{\prime}$-probe) to a DNA sequence in the $5^{\prime}$ flanking region of the HCII gene; both probes hybridized to sequences external to the targeting vector (Figure 1a). Cells from a correctly targeted clone were injected into C57BL/6 blastocysts, which were then implanted into pseudopregnant females. The resulting chimeric males were crossed with wild-type $\mathrm{C} 57 \mathrm{BL} / 6$ females to produce $\mathrm{F}_{1}$ agouti offspring that were genotyped by Southern hybridization of DNA from tail biopsies. $\mathrm{F}_{1}$ heterozygotes were crossed to produce homozygous HCII-deficient mice. These mice were backcrossed for six generations with wild-type C57BL/ 6 animals to produce a nearly congenic strain of mice containing the HCII-null allele. N6 heterozygotes were crossed to produce $\mathrm{HCII}^{+/+}$and $\mathrm{HCII}^{-/-}$mice. $m R N A$ analysis. Total RNA was purified from adult mouse livers by acid phenol-guanidinium thiocyanate-chloroform extraction (23). Northern blots of the RNA were hybridized with an 891-bp cDNA probe encoding the 3' half of exon 2 and all of exons 3 and 4. The blots were hybridized separately with a 625-bp probe to the neo cassette.

Western blots. Plasma $(0.1$ or $0.3 \mu \mathrm{l})$ was subjected to electrophoresis on a 7.5\% SDS polyacrylamide gel under reducing conditions. The proteins were transferred to a nitrocellulose membrane, which was then blocked with $5 \%$ milk and incubated with affinity-purified goat antihuman HCII IgG (Affinity Biologicals Inc., Hamilton, Ontario, Canada) at a concentration of $3 \mu \mathrm{g} / \mathrm{ml}$ for 1 hour at room temperature. The membrane was subsequently washed and incubated with horseradish peroxidase-conjugated mouse anti-goat IgG (A9452; Sigma Chemical Co., St. Louis, Missouri, USA) at a 1:5000 dilution. Immobilized antibody was detected with SuperSignal West Pico Chemiluminescent Substrate (Pierce Chemical Co., Rockford, Illinois, USA) according to the manufacturer's instructions.

Inbibitor activity assays. HCII activity was determined by measuring the amount of thrombin inhibited in mouse plasma supplemented with dermatan sulfate. Plasma $(2 \mu \mathrm{l})$ was mixed with $50 \mu \mathrm{g} / \mathrm{ml}$ porcine skin dermatan sulfate (Sigma Chemical Co.) and $16 \mathrm{nM}$ human $\alpha$-thrombin (Haematologic Technologies Inc., Essex Junction, Vermont, USA) in a total volume of 100 $\mu \mathrm{l}$ of buffer containing $50 \mathrm{mM}$ Tris- $\mathrm{HCl}, 150 \mathrm{mM}$ $\mathrm{NaCl}$, and $1 \mathrm{mg} / \mathrm{ml}$ poly(ethylene glycol) 8000, $\mathrm{pH} 7.4$ (TS/PEG buffer). Thrombin was added last to initiate 
the reaction. After a 60 -second incubation at room temperature, $500 \mu \mathrm{l}$ of $100 \mu \mathrm{M}$ tosyl-Gly-Pro-Arg- $p$ nitroanilide (Chromozym TH; Roche Molecular Biochemicals, Indianapolis, Indiana, USA) in TS/PEG was added, and the absorbance at $405 \mathrm{~nm}$ was determined continuously for 100 seconds. The rate of change of absorbance was proportional to the concentration of active thrombin that remained in the incubation. The molar concentration of HCII in plasma was calculated from the amount of thrombin inhibited, assuming 1:1 stoichiometry of inhibition.

Antithrombin activity was determined by measuring the amount of factor Xa inhibited in plasma supplemented with heparin. Plasma $(0.3 \mu \mathrm{l})$ was mixed with 1 $\mathrm{U} / \mathrm{ml}$ porcine intestinal heparin (Elkins-Sinn Inc., Cherry Hill, New Jersey, USA) and $11 \mathrm{nM}$ human factor $\mathrm{Xa}$ (Haematologic Technologies) in $100 \mu \mathrm{l}$ of TS/PEG buffer. Factor Xa was added last to initiate the reaction. After a 60-second incubation at room temperature, 500 $\mu \mathrm{l}$ of $500 \mu \mathrm{M} \mathrm{MeO}-\mathrm{CO}-\mathrm{D}-$ cyclohexylglycyl-Gly-Arg-pnitroanilide (Spectrozyme fXa; American Diagnostica Inc., Greenwich, Connecticut, USA) in TS/PEG was added, and the absorbance at $405 \mathrm{~nm}$ was determined continuously for 100 seconds. The rate of change of absorbance was proportional to the concentration of active factor $\mathrm{Xa}$ that remained in the incubation. The molar concentration of antithrombin was calculated from the amount of factor Xa inhibited, assuming 1:1 stoichiometry of inhibition.

Blood tests. Routine blood tests of four $\mathrm{HCII}^{-/-}$males, four $\mathrm{HCII}^{-/-}$females, four $\mathrm{HCII}^{+/+}$males, and three $\mathrm{HCII}^{+/+}$females, all approximately 6 months of age, were performed using standard methods in the Division of Comparative Medicine, Washington University. The tests included complete blood counts with white blood cell differentials and assays for urea nitrogen, creatinine, total protein, alanine aminotransferase, and aspartate aminotransferase.

Necropsies. Necropsies of four $\mathrm{HCII}^{-/-}$mice approximately 6 months of age (two males and two females) were performed by a veterinary pathologist in the Division of Comparative Medicine, Washington University. Histologic examination included the lung, heart, stomach, intestinal tract, brain, liver, kidney, spleen, pancreas, aorta, adrenal glands, ovary, uterus, testes, and accessory sex glands.

Arterial thrombosis model. Carotid artery thrombosis was induced as described previously (24). Briefly, adult male and female mice were anesthetized with intraperitoneal sodium pentobarbital, secured in the supine position, and placed under a dissecting microscope. The right common carotid artery was isolated through a midline cervical incision, and an ultrasonic flow probe (model 0.5 VB; Transonic Systems Inc., Ithaca, New York, USA) was applied. A 1.5-mW, 540-nm laser beam (Melles Griot Inc., Carlsbad, California, USA) was applied to the artery from a distance of $6 \mathrm{~cm}$. Rose bengal dye $(50 \mathrm{mg} / \mathrm{kg}$ body weight; Fisher Scientific Co., Fair Lawn, New Jersey, USA) was then injected into the

tail vein, and flow in the vessel was monitored until complete occlusion occurred. Five minutes before the injection of rose bengal dye, some animals were injected with purified human HCII (25) or ovalbumin (Sigma Chemical Co.) in PBS to achieve a plasma concentration of about $1 \mu \mathrm{M}$. Specifically, $6.7 \mu \mathrm{l}$ of a $4.7 \mu \mathrm{M}$ protein solution was injected per gram body weight; the plasma volume was assumed to be $31.5 \mu \mathrm{l} / \mathrm{g}$. Carotid artery seg-

\section{a}
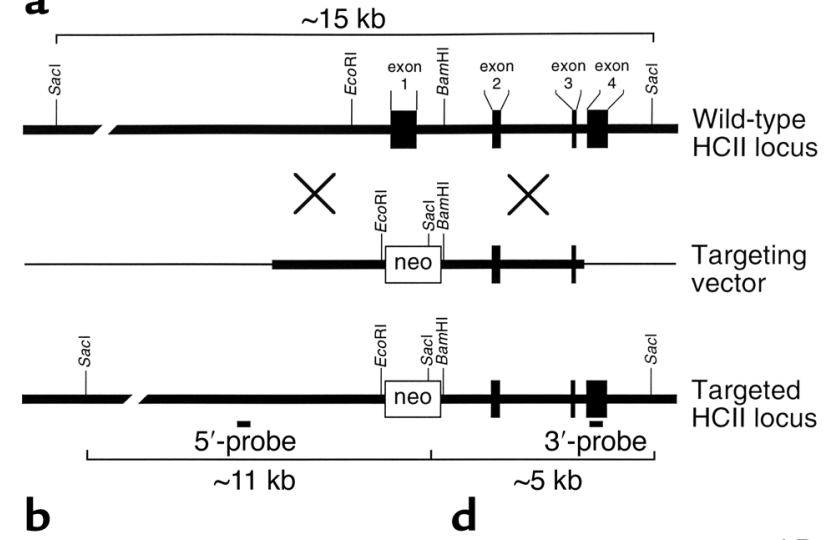

\section{3'-probe}

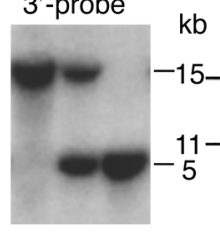

$x^{x} x^{\prime} \lambda^{\prime}$

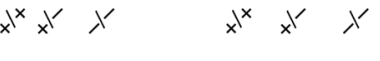

c

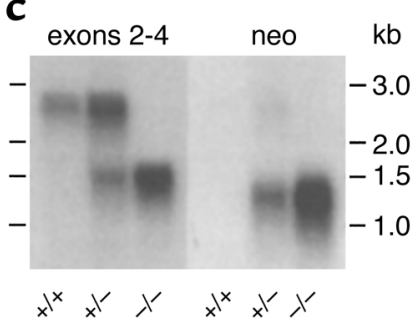

\section{Figure 1}

Targeted disruption of the murine $\mathrm{HCll}$ gene. (a) Restriction map of the $\mathrm{HCll}$ locus and design of a replacement vector. The boxes represent exons 1-4 of the $\mathrm{HCll}$ gene. The thick lines represent genomic DNA; the thin lines, vector DNA. The targeting vector was constructed by insertion of the neomycin phosphotransferase gene (neo) between the EcoRI and BamHI sites of the HCIl gene. (b) Southern blots of genomic DNA isolated from the tails of 4- to 6-week-old mice and digested with Sacl. The restriction fragments were detected with probes ( $5^{\prime}$-probe and $3^{\prime}$-probe) that hybridized with sequences external to the genomic DNA present in the targeting vector. (c) Northern blot of total liver RNA obtained from adult mice. The blot was first hybridized with a cDNA probe containing sequences present in exons 2-4 of the HCll gene. It was then stripped and rehybridized with a probe containing sequences present in the neo cassette. (d) Western blot of mouse plasma probed with goat anti-human HCII IgG. The $68-\mathrm{kDa}$ and $72-\mathrm{kDa}$ bands represent two glycoforms of $\mathrm{HCll}$ that are present in normal mouse plasma (22). HCIl genotypes (+/+, +/-, and -/-) are indicated in panels $\mathbf{b}-\mathbf{d}$. 

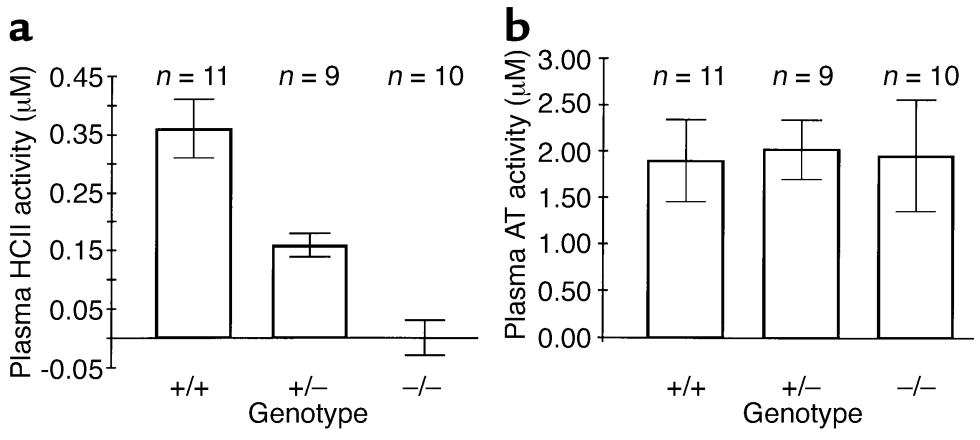

\section{Figure 2}

Biochemical assays of mouse plasma. (a) HCll activity is expressed as the amount of thrombin inhibited per liter of plasma in the presence of dermatan sulfate. (b) Antithrombin (AT) activity is expressed as the amount of factor $X a$ inhibited per liter of plas$\mathrm{ma}$ in the presence of heparin. ments were fixed in $10 \%$ formalin, cross-sectioned, and stained with hematoxylin and eosin for examination by light microscopy.

Statistical analysis. Statistical significance was determined with the Student two-tailed $t$ test (http://faculty.vassar.edu/lowry/VassarStats.html). A $P$ value less than 0.05 was considered significant.

\section{Results}

A cDNA clone for murine HCII was isolated previously, and Southern hybridization of genomic DNA indicated the presence of a single HCII gene (22). In the current study, genomic clones were isolated from a BAC library constructed with DNA from 129/SvJ mice. A partial restriction map of the HCII locus is shown in Figure 1a. A targeting vector was constructed by insertion of the neomycin phosphotransferase gene (neo) between the $E c o$ RI and $B a m H I$ sites of the HCII gene, which resulted in deletion of about $1 \mathrm{~kb}$ of $5^{\prime}$ flanking sequence, exon 1 , and part of intron 1 . Since exon 1 encodes approximately the N-terminal half of HCII, any gene product synthesized from the targeted locus would be expected to be inactive. RW-4 embryonic stem cells derived from 129/SvJ mice were transfected with the linearized targeting vector and selected for growth in the presence of G418. Homologous recombination at the HCII locus was detected by Southern blotting with a probe that hybridized to a DNA sequence in exon 4, external to the genomic sequence included in the targeting vector. Digestion of DNA with SacI yielded a $15-\mathrm{kb}$ fragment from the wild-type allele and $\mathrm{a} 5 \mathrm{-kb}$ fragment from the targeted allele.

Homologous recombination occurred in 5 of 684 G418-resistant embryonic stem cell clones. Embryonic stem cells from one clone with the targeted allele were injected into C57BL/ 6 blastocysts and implanted into pseudopregnant females. The resulting chimeric males were crossed with wild-type C57BL/ 6 females to produce $F_{1}$ offspring that were genotyped by Southern blotting of DNA from tail biopsies. Correct targeting of the $H C I I$ locus was verified with probes that hybridized to sequences both $5^{\prime}$ and $3^{\prime}$ to the DNA included in the targeting vector (Figure $1 \mathrm{~b}$ ). Crosses of heterozygous $\mathrm{F}_{1}$ animals yielded 250 offspring, with $\mathrm{HCII}^{-/-}$pups being present at close to the expected mendelian frequency (24.8\% $\mathrm{HCII}^{+/+}$, 53.6\% $\mathrm{HCII}^{+/-}$, and 21.6\% $\left.\mathrm{HCII}^{-/-}\right)$. Subsequent crosses in which both parents were $\mathrm{HCII}^{-/-}$pro- duced litters similar in size $(6.8 \pm 3.0$ pups per litter, $n=11$ litters) to those obtained from crosses of $\mathrm{HCII}^{+/-}$ mice $(6.7 \pm 3.1$ pups per litter, $n=38$ litters).

Northern blots of total liver RNA isolated from adult $\mathrm{HCII}^{+/+}$mice demonstrated a single HCII mRNA species of about $2.5 \mathrm{~kb}$, as expected from previous studies (22); this mRNA was absent in $\mathrm{HCII}^{-/-}$mice (Figure 1c). A 1.2$\mathrm{kb}$ transcript containing neo sequences was detected in $\mathrm{HCII}^{+/-}$and $\mathrm{HCII}^{-/-}$mice but not in wild-type animals. A separate, $1.4-\mathrm{kb}$ transcript containing sequences present in exons 2-4 of the $\mathrm{HCII}$ gene was also present in $\mathrm{HCII}^{+/-}$ and $\mathrm{HCII}^{-/-}$mice. Since plasma from $\mathrm{HCII}$-null mice did not contain detectable HCII antigen or activity (see below), the 1.4-kb transcript was not investigated further.

Western blots of plasma probed with a polyclonal antibody indicated the presence of two previously described glycoforms of HCII (68 kDa and $72 \mathrm{kDa}$ ) in wild-type mice (22). Both glycoforms were absent in $\mathrm{HCII}^{-/-}$mice, and intermediate levels were present in $\mathrm{HCII}^{+/-}$mice (Figure 1d). No bands of lower molecular weight were observed in plasma of mice with the targeted HCII allele, strongly suggesting that the abnormal 1.4-kb HCII transcript did not give rise to HCII-like polypeptides in the circulation. Biochemical assays confirmed the absence of HCII activity (i.e., dermatan sulfate-dependent thrombin inhibition) in plasma obtained from $\mathrm{HCII}^{-/}$mice $(0.00 \pm 0.03 \mu \mathrm{M}$, mean $\pm \mathrm{SD})$ in contrast to $\mathrm{HCII}^{+/-}$ $(0.16 \pm 0.02 \mu \mathrm{M})$ and $\mathrm{HCII}^{+/+}(0.36 \pm 0.05 \mu \mathrm{M})$ mice (Figure 2a). Antithrombin activity (i.e., heparin-dependent factor Xa inhibition) was similar in all three genotypes (Figure 2b).

At one year of age, homozygous HCII-deficient mice were indistinguishable from their wild-type and heterozygous littermates in weight, appearance, and survival. Necropsies of four adult $\mathrm{HCII}^{-/-}$animals revealed no gross or microscopic abnormalities. Blood tests of $\mathrm{HCII}^{-/-}$ mice $(n=8)$, including complete blood count with white blood cell differential, urea nitrogen, creatinine, total protein, alanine aminotransferase, and aspartate aminotransferase, were within normal limits and did not differ significantly from those of wild-type mice $(n=7)$.

The time to formation of an occlusive thrombus in the carotid artery following photochemically induced endothelial injury was shorter in HCII-deficient mice than in wild-type controls. Previous studies indicated that the base-line occlusion time in this model varies with 

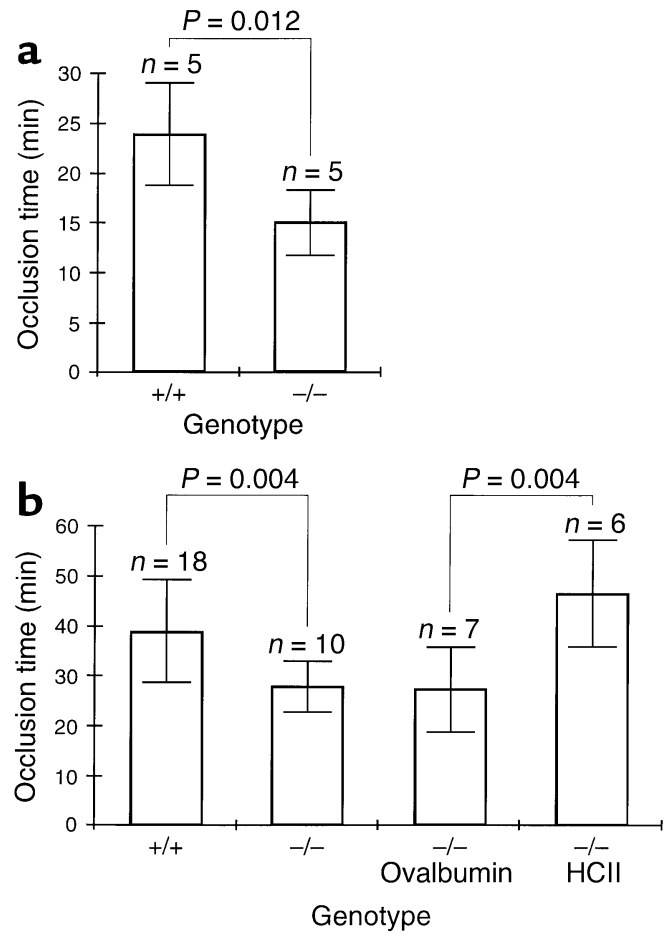

the mouse strain (26). For our initial experiments, $\mathrm{HCII}^{-/}$ mice and their $\mathrm{HCII}^{+/+}$littermates were studied at 6-8 months of age. These animals were obtained from crosses of heterozygous $F_{1}$ animals to insure that potential modifier genes present in the C57BL/ 6 and $129 /$ SvJ backgrounds would be distributed at equal frequencies in both sets of animals (Figure 3a). The time to arterial occlusion was $14.9 \pm 3.2$ minutes in $\mathrm{HCII}^{-/-}$mice compared with $23.7 \pm 5.1$ minutes in $\mathrm{HCII}^{+/+}$mice (mean \pm $\mathrm{SD}, n=5$ in each group). This difference is statistically significant $(P=0.012)$. To determine whether the difference in occlusion time is reproducible in mice with a more homogeneous genetic background, HCII heterozygotes were backcrossed for six generations with wild-type C57BL/6 animals to yield animals with about $97 \%$ C57BL/6 gene content. The N6 heterozygotes were crossed to produce $\mathrm{HCII}^{+/+}$and $\mathrm{HCII}^{-/-}$mice, which were studied at 3-4 months of age. In the $\mathrm{HCII}^{-/-}$mice, the time to arterial occlusion was $27.7 \pm 5.0$ minutes $(n=10)$

\section{Figure 3}

Effect of HCll deficiency on thrombotic occlusion of the carotid artery. Blood flow in the common carotid artery was monitored continuously with an ultrasonic flow probe. Local endothelial injury was induced by application of a $540-\mathrm{nm}$ laser beam to the carotid artery followed by injection of rose bengal dye $(50 \mathrm{mg} / \mathrm{kg})$ into the lateral tail vein. (a) Mice with a mixed C57BL/6-129/SvJ genetic background. (b) Mice backcrossed for six generations into the $\mathrm{C} 57 \mathrm{BL} / 6$ background. Five minutes before the injection of rose bengal dye, some of these mice were injected intravenously with purified human $\mathrm{HCll}$ or ovalbumin as indicated to achieve a plasma level of about $1 \mu \mathrm{M}$.

compared with $38.6 \pm 10.2$ minutes in the $\mathrm{HCII}^{+/+}$mice $(n=18)$ (Figure 3b). Although the occlusion times of both the wild-type and the HCII-null animals were longer than those of mice with a mixed genetic background, the absolute difference was similar (11 minutes vs. 9 minutes) and was statistically significant $(P=0.004)$. The abnormally short arterial occlusion time of the $\mathrm{HCII}^{-/-}$mice was corrected by intravenous injection of purified HCII 5 minutes prior to induction of vascular injury $(46.7 \pm 10.8$ minutes, $n=6$ ) but not by injection of the noninhibitory serpin ovalbumin (27.4 \pm 8.5 minutes, $n=7)$ (Figure $3 b$ ).

Representative recordings of carotid blood flow are shown in Figure 4a. Cessation of blood flow was accompanied by the appearance of a pearly white occlusive filling defect in the lumen of the artery that was visible through the dissecting microscope. Sections of the occluded arteries stained with hematoxylin and eosin revealed no gross histologic differences between thrombi formed in $\mathrm{HCII}^{+/+}$and $\mathrm{HCII}^{-/-}$animals (Figure 4, b and c). It was apparent from transient reductions in blood flow as well as direct observation through the dissecting microscope that a dynamic state of thrombus formation and lysis occurred throughout the period of vascular injury prior to complete occlusion.

\section{Discussion}

Unlike antithrombin-deficient mice, which die in utero with extensive fibrin(ogen) deposition in the liver and myocardium (27), HCII-deficient mice apparently undergo normal fetal development and are born at the expected mendelian frequency. Their subsequent growth and survival is normal up to at least 1 year of age, and they do not demonstrate any obvious morphologic

\section{Figure 4}

Thrombotic occlusion of the carotid artery. (a) Representative blood flow recordings of $\mathrm{HCll}^{-/-}$(red) and $\mathrm{HCll}^{+/+}$ (blue) mice. Rose bengal dye was injected at time $=0 \mathrm{~min}$. (b and $\mathbf{c}$ ) Photomicrographs of cross sections of carotid arteries from $\mathrm{HCll}^{+++}$and $\mathrm{HCll}^{-/-}$mice, respectively, harvested after complete cessation of blood flow. The sections were stained with hematoxylin and eosin. a

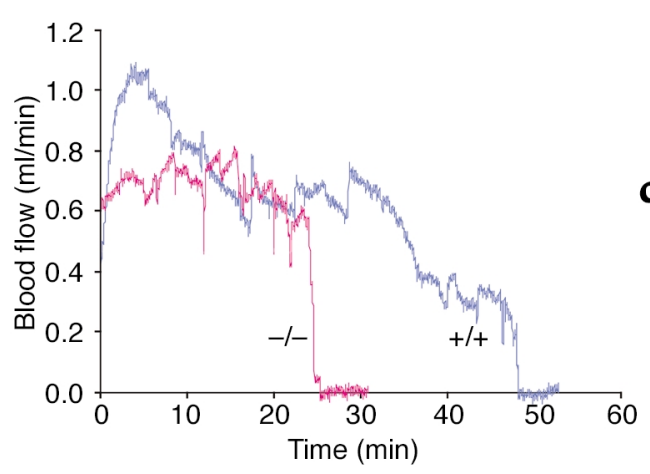

b

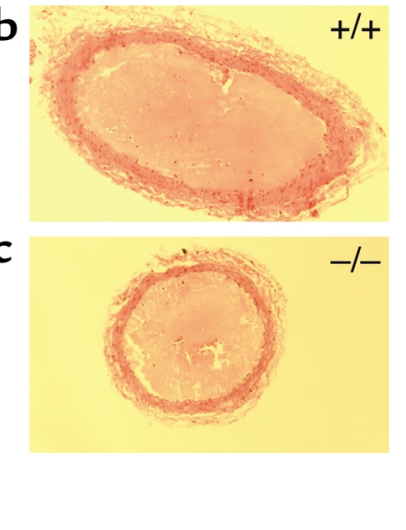


abnormalities on gross or microscopic examination. Blood tests also indicate normal hematopoiesis as well as normal liver and kidney function. Thus, we find no evidence of thrombosis or bleeding secondary to disseminated intravascular coagulation, which are typical manifestations of deficiencies of several other anticoagulant proteins, including protein C (28), tissue factor pathway inhibitor (29), and antithrombin (27). Further experiments may show that HCII deficiency is similar to protein $Z$ deficiency, in which a spontaneous prothrombotic phenotype occurs only when combined with the homozygous factor $V_{\text {Leiden }}$ genotype (30).

Indirect evidence suggests that HCII activity may be increased in human pregnancy. During the third trimester, plasma HCII levels are about $150 \%$ of normal $(31,32)$, both maternal and fetal plasma contain trace amounts of a dermatan sulfate proteoglycan that stimulates thrombin inhibition by HCII (14), and thrombinHCII complexes are elevated approximately fourfold (8). Conversely, HCII levels are decreased to about $50 \%$ of normal in women with severe pre-eclampsia (32), suggesting that decreased HCII activity may be associated with placental dysfunction. Nevertheless, HCII does not appear to be required for normal gestation in mice, since crosses in which both parents are HCII-deficient produce litters similar in size to those from heterozygous matings.

In contrast to the benign phenotype of unchallenged HCII-deficient mice, our experiments suggest that HCII plays an important role in maintaining blood flow after injury to the arterial endothelium. In these experiments, rose bengal dye in the lumen of the carotid artery was excited by transillumination with a green light laser to generate singlet oxygen. Previous studies have shown that this treatment causes membrane damage, resulting in detachment of the endothelial cells from a localized segment of the vessel wall followed by formation of a thrombus that is rich in platelets and fibrin (33). The mean time to thrombotic occlusion of the carotid artery was significantly shorter in HCII-deficient mice than in their wild-type littermates, both in a mixed C57BL/6-129/SvJ background and in a nearly congenic C57BL/6 strain. In a previous study, the carotid occlusion time was reduced to a similar degree in apoE-deficient mice fed a high-cholesterol diet (34). By contrast, the occlusion time was prolonged approximately twofold in mice deficient in plasminogen activator inhibitor-1 $(24,35)$. Thus, the rose bengal model appears to be sensitive to structural alterations in the vessel wall associated with atherosclerosis as well as to systemic changes in the fibrinolytic system. The abnormally short occlusion time of HCII-deficient mice was corrected by intravenous injection of purified HCII (2.1 $\mu \mathrm{g} / \mathrm{g}$ ) to achieve a plasma concentration of about $1 \mu \mathrm{M}$ prior to photochemical injury. As reported previously, intravenous injection of a much larger dose of purified HCII $(84 \mu \mathrm{g} / \mathrm{g})$ prior to photochemical injury of the femoral artery prolonged the occlusion time from 17 minutes to 31 minutes in wild-type rats (36). This experiment, together with our results, suggests that
HCII exerts an antithrombotic effect after photochemical injury to the arterial endothelium.

An important question raised by these studies is whether the protective effect of HCII depends on catalysis of the thrombin-HCII reaction by glycosaminoglycans in the vessel wall. Purified human HCII inhibits thrombin with second-order rate constants of about $6 \times 10^{4} \mathrm{M}^{-1}$ $\mathrm{min}^{-1}$ in the absence of a glycosaminoglycan and about 2 $\times 10^{8} \mathrm{M}^{-1} \mathrm{~min}^{-1}$ in the presence of dermatan sulfate or heparin (37). If one assumes that mouse HCII inhibits thrombin with similar kinetics and is present in plasma at a concentration of $0.35 \mu \mathrm{M}$ (Figure 2), then the halftime for inhibition of thrombin by HCII in mouse plasma would be about 30 minutes in the absence of a glycosaminoglycan. However, it is likely that antithrombin dominates thrombin inhibition in the fluid phase, because it is present at a higher concentration in plasma ( $2 \mu \mathrm{M}$, Figure 2$)$ and it inhibits thrombin more rapidly than HCII does in the absence of a glycosaminoglycan (1). Binding of HCII to subendothelial glycosaminoglycans could potentially concentrate the HCII and dramatically increase the rate of thrombin inhibition at the site of arterial injury. Consistent with this hypothesis, Hatton et al. (38) demonstrated uptake of radiolabeled HCII into the vessel wall and formation of high- $M_{\mathrm{r}}$ complexes (presumably thrombin-HCII) following damage to the rabbit aortic endothelium with a balloon catheter. Future experiments in which HCII-deficient mice are reconstituted with native recombinant $\mathrm{HCII}$ along with variants defective in binding to dermatan sulfate or heparin $(39,40)$ may provide direct evidence for activation of HCII by glycosaminoglycans in the carotid thrombosis model.

The identification of an abnormal phenotype in the HCII knockout mouse does not eliminate the importance of searching for additional abnormalities. Thus, it will be important to determine if HCII-deficient mice are more susceptible to venous thrombosis after endothelial injury or develop thrombi spontaneously within normal blood vessels when another thrombophilic mutation (e.g., homozygosity for factor $V_{\text {Leiden }}$ ) is also present. Since HCII inhibits arterial thrombosis after endothelial injury, it might affect other arterial processes such as atherosclerosis, in which abnormalities in HCII-activating glycosaminoglycans have been demonstrated (13). The HCII-deficient mouse provides a valuable tool with which to explore the regulation of physiologic processes involving thrombin.

\section{Acknowledgments}

The authors wish to thank Elaine Ross for her assistance with the electroporation and culture of embryonic stem cells, Pam Goda and Ron McCarthy for performing blastocyst injections, and Marie La Regina for performing the necropsies. This work was supported by NIH R01 grants HL-55520 (to D.M. Tollefsen) and HL-36195 (to D.T. Eitzman). L. He is supported by NIH training grant T32 HL-07088. C.P. Vicente is supported by a postdoctoral fellowship grant from the Conselho Nacional de Desenvolvimento Científico e Tecnológico (CNPq) of Brazil. 
1. Tollefsen, D.M. 2001. Antithrombin deficiency. In The metabolic and molecular bases of inherited disease. 8th edition. C.R. Scriver, A.L. Beaudet, W.S. Sly, and D. Valle, editors. McGraw-Hill. New York, New York, USA. 4455-4471.

2. Jenny, N.S., and Mann, K.G. 2001. Thrombin. In Hemostasis and thrombosis: basic principles and clinical practice. 4th edition. R.W. Colman, J. Hirsh, V.J. Marder, A.W. Clowes, and J.H. George, editors. Lippincott Williams \& Wilkins. Philadelphia, Pennsylvania, USA. 171-189.

3. Coughlin, S.R. 2000. Thrombin signalling and protease-activated receptors. Nature. 407:258-264.

4. Tollefsen, D.M., Pestka, C.A., and Monafo, W.J. 1983. Activation of heparin cofactor II by dermatan sulfate. J. Biol. Chem. 258:6713-6716.

5. Maimone, M.M., and Tollefsen, D.M. 1990. Structure of a dermatan sulfate hexasaccharide that binds to heparin cofactor II with high affinity. J. Biol. Chem. 265:18263-18271.

6. McGuire, E.A., and Tollefsen, D.M. 1987. Activation of heparin cofactor II by fibroblasts and vascular smooth muscle cells. J. Biol. Chem. 262:169-175.

7. Shirk, R.A., Church, F.C., and Wagner, W.D. 1996. Arterial smooth muscle cell heparan sulfate proteoglycans accelerate thrombin inhibition by heparin cofactor II. Arterioscler. Thromb. Vasc. Biol. 16:1138-1146.

8. Liu, L., et al. 1995. Inhibition of thrombin by antithrombin III and heparin cofactor II in vivo. Thromb. Haemost. 73:405-412.

9. Andersson, T., et al. 1996. Thrombin-inhibitor complexes in the blood during and after delivery. Thromb. Res. 82:109-117.

10. Tollefsen, D.M., and Pestka, C.A. 1985. Heparin cofactor II activity in patients with disseminated intravascular coagulation and hepatic failure. Blood. 66:769-774

11. Sié, P., Dupouy, D., Pichon, J., and Boneu, B. 1985. Turnover study of heparin cofactor II in healthy man. Thromb. Haemost. 54:635-638.

12. Cooper, S.T., et al. 1996. Vascular localization of the heparin-binding serpins antithrombin, heparin cofactor II, and protein C inhibitor. Clin. Appl. Thromb. Hemost. 2:185-191.

13. Shirk, R.A., Parthasarathy, N., San Antonio, J.D., Church, F.C., and Wagner, W.D. 2000. Altered dermatan sulfate structure and reduced heparin cofactor II-stimulating activity of biglycan and decorin from human atherosclerotic plaque. J. Biol. Chem. 275:18085-18092.

14. Andrew, M., et al. 1992. An anticoagulant dermatan sulfate proteoglycan circulates in the pregnant woman and her fetus. J. Clin. Invest. 89:321-326.

15. Brennan, M.J., Oldberg, A., Pierschbacher, M.D., and Ruoslahti, E. 1984 Chondroitin/dermatan sulfate proteoglycan in human fetal membranes: demonstration of an antigenically similar proteoglycan in fibroblasts. $J$. Biol. Chem. 259:13742-13750.

16. Church, F.C., Pratt, C.W., and Hoffman, M. 1991. Leukocyte chemoattractant peptides from the serpin heparin cofactor II. J. Biol. Chem. 266:704-709.

17. Sié, P., Dupouy, D., Pichon, J., and Boneu, B. 1985. Constitutional heparin co-factor II deficiency associated with recurrent thrombosis. Lancet. 2:414-416.

18. Tran, T.H., Marbet, G.A., and Duckert, F. 1985. Association of hereditary heparin co-factor II deficiency with thrombosis. Lancet. 2:413-414.

19. Andersson, T.R., Larsen, M.L., Handeland, G.F., and Abildgaard, U. 1986. Heparin cofactor II activity in plasma: application of an automated assay method to the study of a normal adult population. Scand. J. Haematol. 36:96-102.

20. Bertina, R.M., van der Linden, I.K., Engesser, L., Muller, H.P., and Brommer, E.J.P. 1987. Hereditary heparin cofactor II deficiency and the risk of development of thrombosis. Thromb. Haemost. 57:196-200.

21. Villa, P., et al. 1999. Hereditary homozygous heparin cofactor II defi- ciency and the risk of developing venous thrombosis. Thromb. Haemost 82:1011-1014.

22. Zhang, G.S., Mehringer, J.H., Van Deerlin, V.M., Kozak, C.A., and Tollefsen, D.M. 1994. Murine heparin cofactor II: purification, cDNA sequence, expression, and gene structure. Biochemistry. 33:3632-3642.

23. Sambrook, J., and Russell, D.W. 2001. Molecular cloning: a laboratory manual. Cold Spring Harbor Laboratory Press. Cold Spring Harbor, New York, USA. 7.4-7.8.

24. Eitzman, D.T., Westrick, R.J., Nabel, E.G., and Ginsburg, D. 2000. Plasminogen activator inhibitor- 1 and vitronectin promote vascular thrombosis in mice. Blood. 95:577-580.

25. Tollefsen, D.M., Majerus, D.W., and Blank, M.K. 1982. Heparin cofactor II. Purification and properties of a heparin-dependent inhibitor of thrombin in human plasma. J. Biol. Chem. 257:2162-2169.

26. Eitzman, D.T., and Westrick, R.J. 2000. Vascular photochemical injury in the mouse. In Contemporary cardiology: vascular disease and injury: preclinical research. D.I. Simon and C. Rogers, editors. Humana Press. Totowa, New Jersey, USA. 95-101.

27. Ishiguro, K., et al. 2000. Complete antithrombin deficiency in mice results in embryonic lethality. J. Clin. Invest. 106:873-878.

28. Jalbert, L.R., et al. 1998. Inactivation of the gene for anticoagulant protein $\mathrm{C}$ causes lethal perinatal consumptive coagulopathy in mice. J. Clin. Invest. 102:1481-1488.

29. Huang, Z.F., Higuchi, D., Lasky, N., and Broze, G.J., Jr. 1997. Tissue factor pathway inhibitor gene disruption produces intrauterine lethality in mice. Blood. 90:944-951.

30. Yin, Z.-F., et al. 2000. Prothrombotic phenotype of protein $Z$ deficiency. Proc. Natl. Acad. Sci. USA. 97:6734-6738.

31. Massouh, M., Jatoi, A., Gordon, E.M., and Ratnoff, O.D. 1989. Heparin cofactor II activity in plasma during pregnancy and oral contraceptive use. J. Lab. Clin. Med. 114:697-699.

32. Bellart, J., et al. 1998. Heparin cofactor II: a new marker for pre-eclampsia. Blood Coagul. Fibrinolysis. 9:205-208.

33. Saniabadi, A.R., Umemura, K., Matsumoto, N., Sakuma, S., and Nakashima, M. 1995. Vessel wall injury and arterial thrombosis induced by a photochemical reaction. Thromb. Haemost. 73:868-872.

34. Eitzman, D.T., Westrick, R.J., Xu, Z., Tyson, J., and Ginsburg, D. 2000. Hyperlipidemia promotes thrombosis after injury to atherosclerotic vessels in apolipoprotein E-deficient mice. Arterioscler. Thromb. Vasc. Biol. 20:1831-1834.

35. Matsuno, H., et al. 1999. Differential role of components of the fibrinolytic system in the formation and removal of thrombus induced by endothelial injury. Thromb. Haemost. 81:601-604.

36. Yamanaga, K., et al. 2000. Heparin cofactor II inhibits thrombus formation in a rat thrombosis model. Thromb. Res. 98:95-101.

37. Derechin, V.M., Blinder, M.A., and Tollefsen, D.M. 1990. Substitution of arginine for Leu444 in the reactive site of heparin cofactor II enhances the rate of thrombin inhibition. J. Biol. Chem. 265:5623-5628.

38. Hatton, M.W.C., et al. 1999. Uptake of heparin cofactor II and antithrombin into the aorta wall after a deendothelializing injury in vivo: comparison with the behaviors of prothrombin and fibrinogen. $J$. Lab. Clin. Med. 133:81-87.

39. Blinder, M.A., Andersson, T.R., Abildgaard, U., and Tollefsen, D.M. 1989. Heparin cofactor IIOslo. Mutation of Arg-189 to His decreases the affinity for dermatan sulfate. J. Biol. Chem. 264:5128-5133.

40. Whinna, H.C., Blinder, M.A., Szewczyk, M., Tollefsen, D.M., and Church, F.C. 1991. Role of lysine 173 in heparin binding to heparin cofactor II. J. Biol. Chem. 266:8129-8135. 